Bomhoff, M., Friele, R. Complaints in long-term care facilities for older persons: why residents do not give 'free advice'. Health Policy: 2016

\begin{tabular}{|l|l|}
$\begin{array}{l}\text { Postprint } \\
\text { Version }\end{array}$ & 1.0 \\
\hline Journal website & https://linkinghub.elsevier.com/retrieve/pii/S0168-8510(16)30287-1 \\
\hline Pubmed link & $\underline{\text { https://www.ncbi.nlm.nih.gov/pubmed/27889081 }}$ \\
\hline DOI & $10.1016 /$ j.healthpol.2016.11.007 \\
\hline
\end{tabular}

This is a NIVEL certified Post Print, more info at http://www.nivel.eu

\title{
Complaints in long-term care facilities for older persons: Why residents do not give 'free advice'
}

\author{
MANJA BOMHOFF ${ }^{\mathrm{A}, \mathrm{B}, *}$, ROLAND FRIELE ${ }^{\mathrm{A}, \mathrm{C}}$ \\ a NIVEL-Netherlands Institute for Health Services Research, Utrecht, The Netherlands \\ b Het Inzichtenlab, Utrecht, The Netherlands \\ c TRANZO, Faculty of Social and Behavioural Sciences, Tilburg University, Tilburg, The \\ Netherlands
}

\begin{abstract}
In health care policies, the right to complain is presented as a key patient right. Complaints are also seen as a potential vehicle for quality improvement. However, in long-term care facilities for older persons in the Netherlands, relatively few complaints are registered.

An explorative qualitative study was performed at three long-term care facilities to examine the ways in which different relevant actors define and relate to complaints. We conducted observations and semi-structured interviews with 76 persons: residents, their family members, nurses, volunteers, middle (facility) and upper (institutional) managers and complaint handling personnel.

Long-term care facilities are social contexts obeying complex social and cultural norms. There are great differences in how complaining and complaints are perceived. For most residents, 'complaining' had strong negative connotations: they expected it would lead to undesirable social consequences that could not outweigh possible advantages. To nurses it was important to hear of residents' dissatisfactions but communicative aspects were challenging. Institutional managers saw complaints as 'free advice' they wished to use to enhance the quality of the care provision. Complaint managers underlined the procedural aspects to complaints.
\end{abstract}

A more appropriate and productive policy on complaints in this health care sector should take these differences into account.

\section{INTRODUCTION}

According to Hirschman's often quoted theory on voice and exit, unsatisfied consumers can choose to leave, or complain [1]. In long-term health care however, exit options are often quite limited. Therefore policy makers in many countries have tried to strengthen consumers' position and enable them to voice their dissatisfaction directly [2]. The right to complain is seen as a key right of patients. Within this legal 
Bomhoff, M., Friele, R. Complaints in long-term care facilities for older persons: why residents do not give 'free advice'. Health Policy: 2016

perspective on complaints, most emphasis is placed on the complaints-handling aspects and redress strategies embedded in the 'rule of law' and 'due process' features of a citizen-oriented public administration [3]. The legal model is complemented by a managerial model that views complaint-handling as a way of retaining customers and as a form of organisational learning [4]. Complaints are thereby expected to act as a form of social regulation [5], and as instruments for improving the quality of care [6]. This results in an emphasis on registration systems and feedback loops [7]. Two different perspectives on complaints thus inform health care policy. On the one hand, complaints are seen as a central patients' right. On the other hand, complaints are seen as a way for consumers to use voice to exert power and thereby impact quality [1]. Several scholars have already pointed out that reality is more complex. Very few persons address their dissatisfactions through a complaint [8] Formal complaints are not representative for how quality is perceived and should therefore be approached with caution [9] and [10] not only because complainants are not necessarily representative for all healthcare users, but also because some topics are more likely to get complaints, than others [11]. It has also been found that what complainants expect and what is achieved by submitting a complaint may differ greatly [12] and [13].

In the Netherlands, a law guaranteeing the right to complain has been in place since 1995. In long-term care facilities for older persons, however, relatively few complaints are registered. This is noteworthy since this specific care sector is not rated more positively by patients than other sectors. If anything, it is a sector that tends to have a negative image in public opinion and media coverage.

It is important to understand why so few complaints are filed in this health care sector. If complaints are seen as a quality indicator, low numbers could signal satisfied health consumers. On the other hand, if complaints are seen as a form of public involvement or consumer power, low numbers of complaints could be a signal of problematic power structures. Finally, from a legal perspective, low numbers of complaints might indicate that complaint procedures are inaccessible. From both of these latter perspectives, low numbers of complaints may be worrisome.

The question is however whether these perspectives are also shared by the different actors who actually make up the context for complaints. There is a need to understand complaints from the perspective of the patients themselves. Most research in the health care sector takes policy paradigms as a starting point and focuses on complaint handling in hospitals [14]. From this research we have learned that complainants primarily want a validation of their complaint, an explanation, an apology and the promise of change [15] and [16]. However, most of this research focuses on patients who have already filed a complaint, not on all potential complainers.

Research into voiced dissatisfaction is complicated by definitional problems. These definitional problems become especially acute when the focus shifts towards the perspective of patients. Legal definitions of complaints or definitions used in policy making do not necessarily match the patients' definitions. This difficulty in researching and recording dissatisfaction has been emphasised by others [17]. Expressions of dissatisfaction can be dynamic, fluid and responsive and are difficult to record, classify or interpret [18]. Unvoiced dissatisfaction is, by definition, even more difficult to observe [19]. Various authors have demonstrated that dissatisfaction and satisfaction are not necessarily opposite ends of the same continuum but form 
Bomhoff, M., Friele, R. Complaints in long-term care facilities for older persons: why residents do not give 'free advice'. Health Policy: 2016

distinct phenomena. Thus, the non-expression of dissatisfaction cannot be equated with the expression of satisfaction [20], [21] and [22].

The possible variation in how complaints are conceptualised makes it important to explicitly research definitional questions, especially when dealing with low numbers of 'official' complaints. In this article we report on research performed on the different perspectives on complaints in three facilities for long-term care for older persons in the Netherlands. We explore possible reasons for the low number of registered complaints. Thereby we investigate the perspectives of the different actors that make up the social context of long-term care facilities to see whether the policy perspectives are shared in practice.

\section{Methods}

Explorative research was conducted in three facilities in the Netherlands during the second half of 2012. In total, thirteen facilities were approached and ten declined. The most often mentioned reason for refusal was the number of studies the facilities were already involved in and the strain this was putting on their staff. The three facilities that did respond were located in different regions, rural and urban. Two of the facilities were 'care homes' in which residents were assisted and basic care was provided and one facility was a 'nursing home'. Residents in this facility were much more dependent on (medical) care and assistance in daily life. All three facilities were part of a larger institution including ten to twenty other facilities, and they were visited by two researchers over the course of four to six days. In order to avoid selection-bias, two selected facilities had a relatively positive (upper 20\%) and one had a relatively negative (lowest 20\%) ranking on a Dutch quality-information site. During the visits, the researchers approached possible respondents in public places like a restaurant, café or waiting area and used the snowball method.

It is important to underline that the focus of this study was on residents, not on complainants. Most research on complaints is conducted among officially registered complainants and records their expectations and experiences. However, since so few residents actually file complaints, the focus of this research was much broader. In Dutch, the word 'klager' can mean 'complainer' as well as 'complainant'. It can thus have the negative connotation of a person who whines, or complains a lot, and the more formalistic and neutral meaning of a person who has issued a formal complaint. Although the same word is used, we found that different persons attached different meanings. Therefore, in translation both words are used.

The main research methods in this study were observations and interviews.

Observations were used to document interactions and experience the accessibility of formal and informal complaint handling procedures. Interviews were conducted in all three facilities with different actors in these settings. In total, 28 residents, 8 family members, 16 nurses, 5 middle managers (at the facility), 3 upper managers (from the organisation) and 3 complaint handling managers were interviewed. In every facility, a selection of other persons was also interviewed such as a priest, receptionists, volunteers, a hairdresser and a physiotherapist. In total 76 persons were interviewed in the course of 68 interviews, as some interviews involved multiple respondents. The interviews were semi-structured and informed by scholarly literature. Standard topics of conversation included attitudes towards complaints and complainers, expectations and experiences. However, respondents were encouraged to give their own opinions and they were given a role in deciding on important topics of 
Bomhoff, M., Friele, R. Complaints in long-term care facilities for older persons: why residents do not give 'free advice'. Health Policy: 2016

conversation. To avoid confirmation-bias the interviewers made sure to intermittently ask open questions and differently formulated questions and analyse the variation in responses. They also asked key-respondents to interpret earlier obtained information. The open, semi-structured interviews usually took between 30 and $60 \mathrm{~min}$. An explicit and careful informed consent procedure was applied that was tailored to the various participants. For the older residents, the most vulnerable group of participants, this meant that they were given both oral and written explanation of the research. They were supplied with contact details of the researchers and they were asked whether they wanted some waiting time between the introduction of the research plus the informed consent procedure and the actual interview. The facilities also agreed beforehand to put up a notice on their notice boards or in their newsletter informing the residents, staff and family about the research and the possibility to participate.

Analysis and data-collection were iterative in a process that showed similarities to the constant comparative method [23]. This means that in some interviews the researchers asked the respondents to react to earlier findings. Particularly, respondents with key positions or respondents who demonstrated the ability to reflect on their personal situation or on more abstract notions were suitable for this process. In this fashion the researchers checked and validated their first findings and conclusions and actively looked for possibly opposing views and facts. Also, datatriangulation took place through the obtained information from the observations and from the interviews. During data-collection there was frequent and active discussion between the researchers and research-assistant about the findings and their possible meanings. An example of a finding that was much discussed was the fact that most respondents would first explain that they had nothing to complain about, only to state more negative experience towards the end of the interview. Another example of such a discussion was on whether the severity of the unfiled complaints could and should be objectified and whether this mattered.

MAXQDA, a software programme to help with qualitative data analysis was used for deductive and inductive coding. Because of the clear, policy related research question and the applied character of this research, the majority of codes were deducted from the research proposal and initial research questions. These were the codes related to categories of actors (such as residents; family members and different professionals and managers). Other deducted codes concerned the different possible routes for complaining; possible actors to whom a complaint could be directed and various aspects of the institution's complaint policy. Inducted codes were themes that recurred during the interviews or that seemed to have explanatory power for not complaining (such as identity and the institutional communication policy). Coding took place after the data collection had ended. It was principally used to structure the data and to counter possible biases. Codes came from the literature and from the researchquestion and related policy expectations. All codes were checked between the principal researcher and the research assistant.

The research findings were communicated in a Dutch report as well as in three separate documents with tailored findings and recommendations for the three participating institutions. Telephonic interviews with managers at all three facilities were conducted to maximise dissemination and social impact and validate the research findings. 
Bomhoff, M., Friele, R. Complaints in long-term care facilities for older persons: why residents do not give 'free advice'. Health Policy: 2016

\section{RESULTS}

In mapping the different perspectives of the actors included in this study, four major views emerged: a residents', a professional, a managerial and a legal view. For most residents, 'complaining' had strong negative connotations. A small minority of residents spoke of complaining in a functional and unproblematic fashion. But most did not. At first residents were often hesitant to talk about their dissatisfaction. Most residents were not prepared to be identified as dissatisfied or as a complainer. When the interviewers brought up the topic of dissatisfaction, most residents hastened to say that they were satisfied by nature. One resident explained: "I do not have any problems. Not with the care personnel. Not with the cleaners. Not with the other staff. No. I can get along with all of them. I will not call them to ask them why they're taking so long. No, I'm not that difficult." And another resident said: "I'm not giving them [the nurses] a lot of work." And yet another one said: "They [the nurses] tell me: If there is one [resident] here who doesn't complain, it's you.” 'Complaining' was very quickly put down to 'being a complainer' or 'being difficult'. Complaining to them had more to do with the person voicing the complaint than with the cause for the complaint. Many interviewed residents took pride in not being demanding and called themselves 'easy-going', 'not difficult' or 'easy to please'. These remarks often surfaced in conversations, many times without any probing. The qualification was made in comparison to other residents. Residents explained that nurses did not deserve to get such complaints. Many stressed that they were liked by the nurses. Several residents narrated experiences in which nurses had come to them to share private information or emotional moments: "They come to me for a cry" or "they all talk to me" or "she told me about her grandchild before she told anybody else". They related these experiences to indicate the nature of their relationships and illustrate their social position. Interestingly, these residents seemed emotionally and socially closer to the staff than to their fellow residents. They saw the nature of these relationships as an important reason why they would not complain.

The few residents who had complained said they had tried to do so very tactfully. They explained how they would choose a specific person and a specific moment to complain. They also had ideas about the way in which complaints could best be conveyed, for instance with humour and not too seriously. They also felt that complaining was not without social consequences and did their best to influence these positively by complaining carefully. But even these clients did not see the complaint manager or the client council as opportune ways to address dissatisfaction. Next to the importance of maintaining positive social relationships, there were also other reasons residents mentioned for not complaining. Some residents stressed their own physical dependency and sense of powerlessness. This issue was most explicitly brought forward by residents who spoke of their fear of repercussions. Although no resident or family member said they had actually experienced repercussions, they did talk about the need to avoid them.

Resident: “I won’t say anything anymore. Otherwise they [nurses] might start hating me”.

Because most residents expected their physical and mental state to deteriorate one day, some explained how they were afraid of what would happen to them when things would get worse. 
Bomhoff, M., Friele, R. Complaints in long-term care facilities for older persons: why residents do not give 'free advice'. Health Policy: 2016

Resident: "You should be nice to them, keep them as your friend. So that when we will be totally impaired, they will still be kind to us."

Researcher: "What could happen otherwise?"

Resident: "Well, the thing is: they are very busy and the time they spend on others, they can't spend on us. That's why we try to do everything we can, ourselves. [...] But for instance if you fall, they will have to come. Because when I broke my hip, they took an hour to sit with me. That was very sweet of them to do that. They held my hand and sat with me until the ambulance came to take me to the hospital [...] but other times when I call I have to wait for half an hour. And then I won't say anything $[\ldots]$ they might start ignoring you”.

The quote shows how a client may experience a sense of gratitude, but also of insecurity and fear and how these emotions may prevent them from voicing possible dissatisfactions.

Many residents also felt dependent on institutional and national policies. 'It is the way it is' some residents and family members said to explain how they felt unable to exert power. Interestingly this attitude was most often expressed about more structural and abstract problems: residents for instance experienced how the care they received could be negatively influenced by the nurses' experienced lack of time or resources. However, these more structural problems were rarely addressed in more formal registered complaints. In interviews too, these topics were often mentioned only at the end of the interview, or after probing. Nevertheless, when these more structural problems were mentioned, they were seen as having great negative consequences. In this context however, residents talked about decisions taken 'higher up' or in 'the Hague', the political capital of the Netherlands, without clearly pointing towards a responsible person or institution. They saw no way of influencing these decisions and did not believe their voice would make a difference and when explaining the current situation often used the same phrases as those offered by nurses. Together, residents and nurses underlined the sense of suffering and powerlessness.

Relative: "Yes, but this is what I tell her too. I say: listen, they, and it's the government's fault, they [nurses] have to work with fewer people, and so they don't have as much time for you as they did when you first came here. You'll have to get used to that".

Resident: "The girls [nurses] say the same thing. They say: we do what we can, but we can only say 'yes' and 'no' now. We can't really chat with you anymore. We don't have the time for that anymore, they say.

Like residents, nurses did not see complaints as separate from the complainer. Many different explanations for complaining were offered and nurses explained how some residents always kept quiet, whereas others were notorious complainers. Nurses also explained how important it was to them to hear of residents' dissatisfactions. Good quality care requires information from patients, they said. Dissatisfaction with members of staff, institutional policy, food or even medical decisions have to be voiced, since it contains basic information about residents' well-being, the quality of the care and the possibilities for improvement. Residents were therefore often encouraged to talk about their dissatisfaction. Nurses said they tried to make residents talk by telling them that they should feel free to complain or by explaining that they did not have to fear retaliation. However, these encouragements did not always address the residents' real worries. 
Bomhoff, M., Friele, R. Complaints in long-term care facilities for older persons: why residents do not give 'free advice'. Health Policy: 2016

Just as some residents were encouraged to talk, others were explicitly curbed. Nurses explained how some residents would not stop complaining, had unrealistic demands or complained because of their mental illness. These residents were told to stop complaining, or were told why their complaint made no sense or would not be effective. Residents also talked about these forms of regulation. Several residents explained that instances in which they had been constrained had been so upsetting that they had decided never to complain again. One care coordinator noticed how these trends sometimes conflicted. On the one hand, residents were encouraged, and on the other hand they were limited. She talked about a resident who she had often advised to complain. According to her, this resident was too scared to ask for a change of diaper and did not call at night because she thought the staff was 'too busy'. She had therefore told this resident how important it was to voice her wishes and needs. When the coordinator was asked how she herself had come to know about this particular problem she explained that she had been able to tell from the injured skin that this resident with incontinence had not been changed often enough. The coordinator explained how she had written notes in the resident's personal care plan and how she had told her colleagues to pay extra attention to this woman's needs. However she said that while some colleagues were likely to take this resident's requests seriously, others put her off by telling her they would attend to her later. 'And that is the problem, I think, for her as well. If she's turned down like that a few times, she will not ask for anything anymore'.

Institutional managers had yet a different outlook on complaints. The three managers in this research were all responsible for several facilities at once and voiced their formal institutional policy. All three explained that all complaints had to be taken seriously and that every expression of dissatisfaction had to be seen as a complaint. The term 'free advice' was frequently used to express their vision on complaints. It showed the importance the institutional managers placed on the role of complaints as both quality markers and quality enhancers.

In addition, the complaint managers who were appointed to take care of official (called: formal) complaints in several facilities, underlined the procedural aspects of their work. All explained how important it was to be unbiased, to hear both sides and to react in timely fashion. Their position, they said, did not allow them to react to anonymous complaints. They also did not find it appropriate to actively invite residents to give feedback, arguing that the complainants themselves were supposed to take the initiative. In other words, they had a strong legalistic approach to their work and position, even though this meant they received only a handful of complaints a year.

A topic that was similarly viewed by both upper managers and complaint managers was registration. Registration both in national health care policy as well as in institutional policy supposed to ensure that complaints lead to long-term structural quality effects. In order for complaints to actively contribute to quality enhancement, they have to form part of a feedback loop. Both complaint managers and institutional managers underlined the importance of registration.

Institutional manager: "You should see complaints as free advice. They give a lot of information about the experiences of people and of their interpretation of the care they receive. I find it very important that clients can express their complaints. We have to listen and really do something to solve it. That is why we register all complaints, also the informal ones [...] By registering we can see what has been 
Bomhoff, M., Friele, R. Complaints in long-term care facilities for older persons: why residents do not give 'free advice'. Health Policy: 2016

done with a complaint. Whether it has been solved or whether certain complaints recur."

However, complaints were registered at the larger managerial level in the institution's official annual reports. Neither complaint managers nor institutional managers had any clear idea of the complaints in individual facilities. The institutional managers interviewed, nevertheless all said they trusted that complaints were effectively registered in their facilities. Nurses on the other hand were downright sceptical. They underlined the definitional problems that made registration difficult if not impossible. These problems, as understandable as they are, were however not a topic of discussion between these different organisational layers. Opportunities outside the regular care activities and the official complaint procedure seemed potentially far more effective for addressing dissatisfaction. In interviews, the intake and the regular yearly or half-yearly evaluation meetings were for instance mentioned as productive moments. In such separate evaluation meetings, nurses have more time to seriously address the reasons why residents may prefer not to speak about their dissatisfaction. Such conversations can also address various positive and negative experiences and can be geared towards improving the care relationship. This makes it easier to label complaints as necessary feedback, a label strongly preferred by most residents, as well as by nurses. Family members and volunteers also played an important role in discerning and addressing dissatisfaction. Moreover, in all three facilities observations indicated additional places and persons that seemed far more suitable for informal complaining, such as the receptionists in one facility and the hairdressers in another. Because of their position at some distance from the regular care relationship, residents seemed to feel more free when talking to them. Perhaps because they can listen without having to solve the problems they hear of. In any case both persons and moments outside of the regular care activities seemed most suitable for an informal discussion of dissatisfactions.

\section{DISCUSSION}

Even though all perspectives are in fact multi-composite, since not all residents, nurses, institutional managers or complaint managers think alike, there was nevertheless a considerable overlap between those in similar positions. Especially so among the institutional managers with their managerial view and the complaint managers with their legal view. Their ways of understanding, defining and talking about complaints mirrored the policy perspectives and were in many ways alike. In the interviews with volunteers, other professionals at the facilities and family members, both the residents' and the professional views surfaced, perhaps because of the intermediary position these persons often take.

Each of these views is based on a different definition of complaints. Within the managerial view, all expressions of dissatisfaction are labelled as complaints and require action as long as they are identifiable and contain valuable quality information. The legal view on the other hand focuses primarily on form and leaves contents out of consideration. Complaints should be made formally, often in writing. Both these views are reflected in policies on complaining in healthcare. The definition of complaints in the professional as well as the residents' view is much less descript and more context-specific. Dissatisfactions do not have to be expressed in a specific form or with a specific content; defining an expression of dissatisfaction as a complaint may in fact harm the social relationship that residents value so dearly. 
Bomhoff, M., Friele, R. Complaints in long-term care facilities for older persons: why residents do not give 'free advice'. Health Policy: 2016

The professional view on complaints seems closest to the residents': it is in the caretakers' and facility managers' best interest to know how residents feel about the care they receive. The information is needed to customise caregiving. Nevertheless, several differences between the professional and the residents' view are potentially problematic. First of all, information about dissatisfaction turns out to be hard to obtain. Residents are encouraged to speak out, but not always in an effective manner since these encouragements do not strike a chord with most residents' real interests or worries. On the other hand, caretakers curb certain residents' expressions of dissatisfaction. They tell residents to have realistic expectations, and explain how other parties make the important decisions. Residents learn how some topics are more suitable for complaints than others [20], [24] and [25]. Also, caretakers regularly repeat that they cannot work harder. Second of all, caretakers also react to complaints by looking for possible solutions, thereby discussing the complaint in teams or with their management. In their encouragement and their restrictions, as well as in their problem-solving activities, caretakers sometimes fail to heed the individual residents' point of view. Worse, nurses sometimes react by disciplining residents which resulted in some vowing to never voice their dissatisfaction again. It is impossible to objectify and measure the severity of the dissatisfactions we recorded that had not lead to complaints. Respondents told of occasions when they had not been able to eat provided food, not been able to go to the toilet for longer periods of time, had experienced pain during treatment and had been given undesired responsibilities in overseeing other-more vulnerable- residents. It is tempting to describe these as serious issues. That would in all fairness however require exactly the truth-seeking residents were not interested in. The most important point therefore is that although these experiences mattered to residents, nurses and managers remained oblivious.

\section{CONCLUSION}

The four views have a fundamentally different approach to complaints. But whereas the managerial and the legal views are reflected in both national and facility policy, the professional and especially the residents' views are not. Most residents considered the specifically designed complaint trajectories to be unfit for a productive discussion of their dissatisfaction. Complaint trajectories focus primarily on procedural aspects such as hearing both sides and finding a solution. The policy models do not take into account the important social contexts within which residents experience dissatisfaction. The registration of complaints, an important component of complaint policy, is therefore little more than' regulatory ritualism [5]. Although the residents' right to complain should be safeguarded and complainants may indeed place much importance on procedural aspects once they have issued a complaint, residents in general have other far more pressing concerns. Both the managerial model and the legal model have a naïve understanding of the function and nature of dissatisfaction and how it is expressed. They pay lip service to patients' needs but do not fit well in this particular health care sector, where patients are residents and receive long-term care in a social setting [26]. National health care policies should leave more room for sector specific adaptations, especially where the informal complaint trajectories are concerned. In this specific sector the creation of informal communication moments and feedback loops both during and separate from the dayto-day caregiving could receive far more attention. 
Bomhoff, M., Friele, R. Complaints in long-term care facilities for older persons: why residents do not give 'free advice'. Health Policy: 2016

This research warns against the rhetoric that sees residents as consumers who easily complain. Residents in long-term care facilities for older persons are not the critical, assertive healthcare users that figure in health care policies [27]. Because of greatly differing views on complaints, managers, complaint managers and policy makers fail to understand what is important to residents. Dissatisfactions should be addressed at the resident level where they matter most, not in formal structures or procedures. As these procedures do not offer compassionate and effective approaches. To more successfully address dissatisfactions of residents, the approach to dissatisfactions should therefore be broadened. First priority should be to continuously invest in informal communication moments between residents, family members, volunteers and personnel. Whilst a formal complaint procedure should be in place for the few who need it, most residents prefer to deal with their dissatisfactions without filing a complaint.

\section{Sources of funding}

This study was funded by the Dutch Ministry of Public Health, Welfare and Sports. The study sponsor had no role in the collection, analysis and interpretation of the data, the writing of the article or the decision to submit the article for publication.

\section{Conflict of interest}

The authors report no conflict of interests.

\section{Acknowledgements}

We would like to express our gratitude towards the inhabitants, the caretakers and all other personnel and managers of the three studied long-term care facilities. Also, we would like to thank Ninke Paus who contributed to the data collection.

\section{REFERENCES}

$[1]$

A. Hirschman

Exit, voice, and loyalty responses to decline in firms, organizations, and states

Harvard University Press, Cambridge (1970)

[2]

M. Schlesinger, S. Mitchell, B. Elbel

Voices unheard: barriers to expressing dissatisfaction to health plans

Milbank Quarterly, 80 (2002), pp. 709-755

[3]

B. Brewer

Citizen or consumer? Complaints handling in the public sector

International Review of Administrative Sciences, 73 (4) (2007), pp. 549-556

[4]

J. Allsop, K. Jones

Withering the citizen, managing the consumer: complaints in healthcare settings

Social Policy \& Society, 7 (2) (2007), pp. 233-243

[5]

J. Braithwaite, T. Makkai, V. Braithwaite

Regulating aged care; ritualism and the new pyramid

Edward Elgar Publishing, Cheltenham (2007)

[6]

P. Bark, C. Vincent, A. Jones, J. Savory

Clinical complaints: a means of improving quality of care

Quality in Health Care, 3 (1994), pp. 123-132

[7] 
Bomhoff, M., Friele, R. Complaints in long-term care facilities for older persons: why residents do not give 'free advice'. Health Policy: 2016

R. Markey, F. Reichheld, A. Dullweber

Closing the customer feedback loop

Harvard Business Review, 87 (12) (2009), pp. 43-47

[8]

M. Howard, M.L. Fleming, E. Parker

Patients do not always complain when they are dissatisfied: implications for service quality and patient safety

Journal of Patient Safety, 9 (4) (2013), pp. 224-231

[9]

T. Reader, A. Gillespie, J. Roberts

Patient complaints in healthcare systems: a systematic review and coding taxonomy

BMJ Quality \& Safety, 23 (8) (2014), pp. 678-689

[10]

R. Bouwman, M. Bomhoff, P. Robben, R. Friele

Patients' perspectives on the role of their complaints in the regulatory process

Health Expectations, 19 (2) (2015), pp. 483-496

[11]

S. Giles, R. Lawton, I. Din, R. McEachan

Developing a patient measure of safety (PMOS)

BMJ Quality and Safety, 22 (7) (2013), pp. 554-562

[12]

M. Bismark, M. Spittal, A. Gogos, R. Gruen, D. Studdert

Remedies sought and obtained in healthcare complaints

BMJ Quality and Safety, 20 (2011), pp. 806-810

[13]

R. Friele, S. Kruikemeier, J. Rademakers, R. Coppen

Comparing the outcome of two different procedures to handle complaints from a patients' perspective

Journal of Forensic and Legal Medicine, 20 (4) (2013), pp. 290-295

[14]

L. Veneau, P. Chariot

How do hospitals handle patients complaints? An overview from the Paris area

Journal of Forensic and Legal Medicine, 20 (2013), pp. 242-247

[15]

S. Lloyd-Bostock, L. Mulcahy

The social psychology of making and responding to hospital complaints: an account model of complaint processes

Law and Policy, 16 (2) (1994), pp. 123-147

[16]

G. Doig

Responding to formal complaints about the emergency department: lessons from the service marketing literature

Emergency Medicine Australasia, 16 (2004), pp. 353-360

[17]

L. Mulcahy

Disputing doctors; the socio-legal dynamics of complaints about medical care

Open University Press, Philadelphia (2003)

[18]

B. Williams, J. Coyle, D. Healy

The meaning of patient satisfaction and explanation of high reported levels

Social Science and Medicine, 47 (9) (1998), pp. 1361-1371

[19]

C. Voorhees, M. Brady, D. Horowitz

A voice from the silent masses: an exploratory and comparative analysis of noncomplainers Journal of the Academy of Marketing Science, 34 (2006), pp. 514-527

[20]

L. Mulcahy, J. Tritter 
Bomhoff, M., Friele, R. Complaints in long-term care facilities for older persons: why residents do not give 'free advice'. Health Policy: 2016

Pathways, pyramids and icebergs? Mapping the links between dissatisfaction and complaints

Sociology of Health \& IIIness, 6 (1998), pp. 825-847

[21]

I. Gal, I. Doron

Informal complaints on health services: hidden patterns, hidden potentials

International Journal of Quality in Health Care, 19 (3) (2007), pp. 158-163

[22]

S. Gal

Between speech and silence

J. Vincent (Ed.), The anthropology of politics; a reader in ethnography, theory and critique, Blackwell Publishing, Oxford (2002)

\section{[23]}

A. Strauss, J. Corbin

Basics of qualitative research; techniques and procedures for developing grounded theory Sage Publications, Thousand Oaks (1998)

[24]

M. Attree

Patients' and relatives' experiences and perspectives of 'Good' and 'Not so Good' quality care

Journal of Advanced Nursing, 33 (4) (2001), pp. 456-466

[25]

B. Beardwood, V. Walters, J. Eyles, S. French

Complaints against nurses: a reflection of the 'new managerialism' and consumerism in health care

Social Science \& Medicine, 48 (3) (1999), pp. 363-374

[26]

R. Sorensen, R. ledema, D. Piper, E. Manias, A. Williams, A. Tuckett

Disclosing clinical adverse events to patients: can practice inform policy?

Health Expectations, 12 (2010), pp. 148-159

[27]

J. Newman, E. Vidler

Discriminating customers, responsible patients, empowered users: consumerism and the modernisation of health care

International Social Policy, 35 (2) (2006), pp. 193-209 